\title{
Ventilation studies in a room climate laboratory
}

\author{
Th. Rüegg, A. Weber \\ Section Building Equipment, Swiss Federal Laboratories for Materials Testing and Research (EMPA), CH-8600 Dïbendorf, Suritzerland
}

\section{INTRODUCTION}

For the investigation of room ventilation, a test chamber was built at EMPA [1]. This chamber can be used to model the thermal and aerodynamic behaviour in real size. This allows studies of thermal comfort and ventilation effectiveness of a variety of different rooms. Also very important is the possibility to investigate the convective interaction of the air with the sinulated thermal mass of the envelope. In the following, the test chamber and two experiments are described.

\section{THE VENTILATION TEST CHAMBER}

The chamber has a maximum floor area of $6.1 \mathrm{~m} \times$ $4.6 \mathrm{~m}$ and a maxinum height of $3 \mathrm{~m}$ and can be adjusted to smaller lengths, widths or heights. Two walls, the floor and the ceiling are constructed of water carrying metal panels. The other two walls are transparent to allow for air flow visualization viewed from outside the room. These wails are built with two Plexiglas sheets forming a channel through which conditioned air is flowing. By controlling the water or air temperatures respectively, it is possible to adjust the inside surface temperatures. The whole surface is divided into 9 separate temperature zones. An air handling unit delivers conditioned air to the room through air terminals which can be placed anywhere between the metal panels of the room envelope. An overview of the conditioning equipment is given in Fig. 1.

All the conditioning parameters appear on a PC monitor and can be controlled manually or by a time step pro-

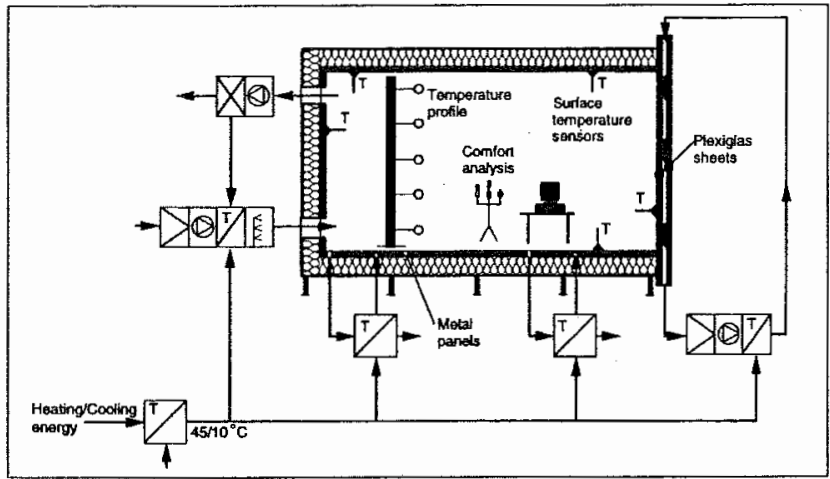

Fig. 1 - Test chamber with conditioning equipment and measuring systems. gram. The wall surface temperatures are measured directly on the surfaces and are used for the closed-loop control of the water supply temperatures. In addition, each surface temperature zone is equipped with heat flow sensors. This allows controlling the surface temperature dynamically, as if it were the surface of a thermally heavy wall making up the envelope of the test room. The heat flow values are used in a finite differences model containing the thermal capacity and conductivity parameters of the wall. The temperature of the wall layers is calculated with the software model giving the actual surface temperature, which is used dynamically as the setpoint of the water conditioning equipment.

Measuring systems in the room include temperature and velocity sensors and a tracer gas system. The data acquisition stores the measurements in a database from which they can be retrieved in the desired combinations.

\section{MODEL VALIDATION FOR A HORIZONTALLY PIVOTED WINDOW}

The multizone airflow calculation program COMIS uses simplified models based on the Bernoulli equation for different types of large openings [2]. The discharge coefficient $C_{d}$ for horizontally pivoted windows needed for the Bernoulli model was evaluated by CFD (Computing Fluid Dynamics) calculations, which on turn had to be validated by measurements in a $1: 1$ scale [3].

The ventilation test chamber was divided into two rooms, one with cold air representing the outside and one with warm air representing the inside, Fig. 2. The partition-wall included the investigated horizontally pivoted window. To determine the airflow through the window, the tracer gas $\mathrm{SF}_{6}$ was injected into the warm room and mixed by a fan until a homogenous concentration of about $6 \mathrm{ppm}$ was reached. Then the window was opened for a short time period. After closing the window and mixing the air in both rooms, the tracer gas concentrations in both rooms were measured again.

The results are shown in Table 1.

The good agreement indicated a well-calibrated CFD model. Comparison between CFD and the Bernoulli model resulted in the following relation between discharge coefficient and tilting angle $\alpha$, window height $\mathrm{H}$ and width $\mathrm{W}$ :

$$
C_{d}=0.0147 \cdot \alpha-0.0928 \cdot \frac{H}{W}+0.04116
$$




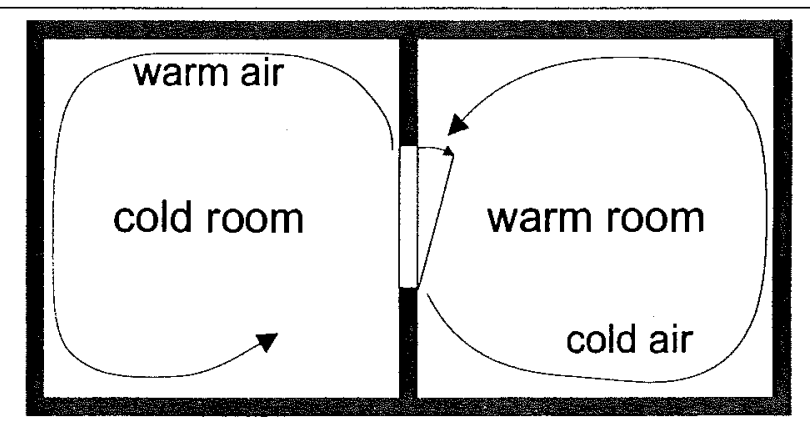

Fig. 2 - Trace of the air after the window has been opened.

Table 1 - Massflow determined by measurements and CFD calculations

\begin{tabular}{|l|c|c|c|c|}
\hline$\Delta T$ between rooms [ $\left.{ }^{\circ} \mathrm{C}\right]$ & 10 & 10 & 10 & 17 \\
Tilting angle $\alpha\left[^{\circ}\right]$ & 90 & 18.7 & 13.6 & 13.6 \\
$\dot{m}$ Measurement $[\mathrm{kg} / \mathrm{s}]$ & 0.147 & 0.050 & 0.036 & 0.047 \\
$\dot{m}$ CFD $[\mathrm{kg} / \mathrm{s}]$ & 0.149 & 0.047 & 0.037 & 0.044 \\
Relative difference [\%] & 1.3 & 6.4 & 5.5 & 6.4 \\
\hline
\end{tabular}

The $\mathrm{C}_{\mathrm{d}}$-value is not dependent on the temperature difference, which means the Bernoulli model is correctly describing the effect of the temperature difference.

\section{EVALUATION OF A NEW METHOD FOR OFFICE COOLING}

For direct cooling of office work places equipped with several computers, a cooling panel called "cool top" was developed, Fig. 3. It is mounted on top of the computer monitors and takes up their convective heat load. The cool top contains car coolers connected to a cooling water supply and small blowers drawing the waste air from the monitors through the coolers. This cooling method should be cheaper than cooling by the room -ntilation system or by cooling panels at the ceiling.

To characterize the cooling capacity of the cool top and its eventual negative influence on the thermal comfort, an office was built in the ventilation test chamber containing a

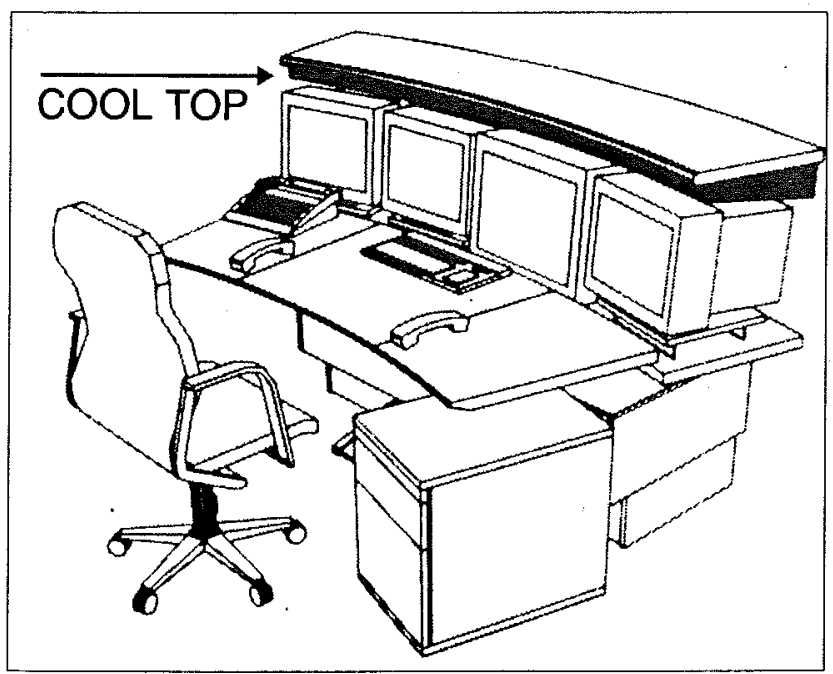

Fig. 3 - Cool top mounted on computer monitors. working place with 4 personal computers and monitors and a cool top mounted above them. Different ventilation methods of low air change were applied to the office: mixing ventilation with a ceiling diffuser, displacement ventilation with a wall diffuser and no ventilation [4].

All three cases showed no degradation of thermal comfort at the working place which was cooled as compared to a point elsewhere in the office. This means that the cooled air was not blown on the working tables in front of the monitors, which could be an objection to this cooling method.

Measurements of the cooling capacity showed that the entire heat load of the monitors could be absorbed by the cool top and even part of the remaining office load. This resulted in a design diagram helpful in planning the cooling water temperatures and blower speeds (voltage) for different cooling loads and room temperatures, Fig. 4.

\section{CONCLUSION}

The studies carried out up to now have shown that there is an important need for experiments in a room climate laboratory, despite the current difficult situation of the construction and building systems branch. The development of new components like the cool top described above, or the application of known ventilation systems in unusal surroundings like a displacement ventilation with floor heating, rely on the possibility that their proper functioning can be demonstrated to the architect and the building owner. This has become very important, because the building systems used are becoming more and more sophisticated.

\section{REFERENCES}

[1] Lommel, A. and Rüegg, Th., 'Die neue Luftströmkammer der EMPA-Abteilung Haustechnik', in 'Energieforschung im Hochbau', Proceedings of 8 . Schweizerisches Status-Seminar, Zürich, September, 1994.

[2] Dorer, V., 'New Large Vertical Opening and Single Sided Ventilation Routines in COMIS', IEA-ECB Annex 23 Technical Report, EMPA 175, April, 1995

[3] Cadloni, M. and Ferrazzini, M., 'Natürlicher Luftaustausch durch Kippfenster', Diplomarbeit, ETH Zürich, 1997.

[4] Oberlin, M. and Kegel, B., 'Messtechnische Ermittlung des Betriebsverhaltens eines Kühltablars', Diplomarbeit, Technikerschule Heizung/Klima Zürich, 1997.

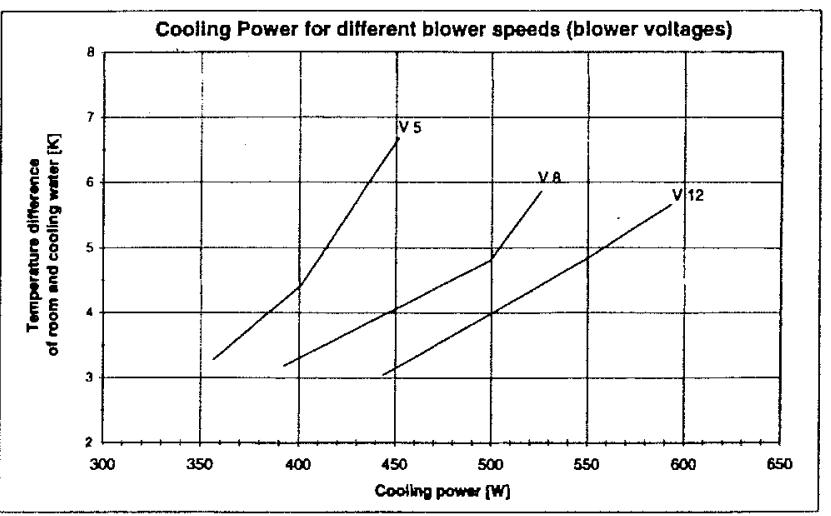

Fig. 4 - Design diagram for the cool top. 